\title{
Health Policy and Ladies Health Workers Stress During Fields Work: Case Study of District Muzaffargarh
}

\author{
Muhammad Hashim ${ }^{* 1}$, Yasir Nawaz Manj ${ }^{2}$, Syed Waqas Shabbir ${ }^{3}$, and Muhammad \\ Rizwan $^{4}$ \\ Department of Sociology and Criminology, University of Sargodha, Pakistan \\ Department of Sociology, Govt. College University, Faisalabad, Pakistan \\ School of Education Science Nanjing Normal University China \\ Corresponding Author: hashimsocial@yahoo.com
}

\begin{abstract}
Lady Health workers are playing a central role in the community health improvement of the nations all over the country. Especially their role in polio eradication, health improvement (Sahit key dastak): campaign cannot be underscored. Working lady health workers facing a whole set of troubles equally in their family as well as in their professional lives such role conflict and overload push them into extreme psychological stress. They have to deal with their job while maintain customary role that overlap household tasks. Hence, in addition to their customary roles, look likes to be one of the key sources of stress that working lady health workers have to face. They take part in their duty as a companion like a mother as well as an earner and give extra time to job also face public extra adverse attitude towards their personal and professional life. The data was reviewed, searched from different search engine that are Google scholar, yahoo, Public policy book Bing, Baidu, Duck Duck GO, the data was taken through the prescribed phone calls.
\end{abstract}

Keywords: Work Place Stress, Lady Health Workers, Fields, Community Health, Stress, 'COVID-19.

\section{Introduction}

Lady Health workers (LHWs) are the (flw's) who are skilled to aid basic healthcare services, health educations to their concern cover areas, that is mostly near to their house or she is living at that village , with in UC of that community. The total number of (LHWs) is more than forty eight thousand approximately in Punjab. Every LHW provide health education and community meetings to 1000 families in to her assigned areas. For this she needs to ensure 10-15 households visits every working day as per government calendar. They are responsible as per Job descriptions for maintaining complete records of family eligible marriage couples, under 15 year girls and boys, Pregnant women record along with polio campaign data and fields work activities during, SIA's, along with daily dairy, register, RI, and family 
planning record. LHWs act as vital health education promoter for the successful delivery of key national intervention such as Polio Eradication Initiative (United Nations, 2015)

There is communication gap between the community and health system. Moreover, in spite of not enough income a major portion was being worn-out on tertiary care therefore neglect primary health care to the rural residents (WHO) .Being a party to Alma Ata declaration, Government of Pakistan with the support ofWHO, showed its obligation by launching a community health workers programme known as the "National Programme for Family Planning and Primary Health Care (FP\&PHC)" in 1994. The Programme popularly identified as "Lady Health Workers Programme" (LHWP), has been able to congregate community contribution through community need creation of awareness and bring about change in attitude about basic issue of health plus family planning by establishing a complete grass roots stage effective system for provision of primary health care (UN Sustainable development goals) .This review work-related to stress faced by lady health workers and its association through self-perceived wellbeing and sick leave between working women. The findings bring it to light that the main factor cause stress among them is 'stress due unfavorable conditions followed by 'increased workload. On the other hand women linked with 'high perceived stress remaining to lower salary associated with conflicts' are reported taking more sick leaves (McCauley M, Madaj B,etl 2018)

Field stress related anxiety in another terms of Psychological stress linked closed to depression, support a lot to work-related ill health, accounting meant for 9.9 million days existence of illness deficiency during the 2014-15, the average, twenty three days lost per person. This is resulted in 35 percent of every one of being missed as of work owed to ill health. The reporting the maximum dominance of ill physical condition as of professionally stress incorporated health in addition to social care, community teaching, community administration and protection (HSE, 2015).

\section{The Stress Response}

Stressors begin physiological response, evolve to defend and protect the human being during the time of threat by means of ensure a reaction (Alexander et al, 2006). This reaction is triggered through the limbic system inside the brain. This is a chain of center calculating emotions that linked to reproductive along with survival behavior's (Blows, 2011). When endurance is threatened by structure is immediately trigger into deed to protect the human being, in spite of the threat degree.A chain response occur: the hypothalamus mediate the autonomic anxious arrangement (Alexander et al, 2006), consequential in a progression of physiological change. The first response is extremely fast, along with only as the in progression reach the cerebrum be able to the need of the circumstances be firm in addition to response adapted

The early flight-or-fight reaction acts resting on the sympathetic dissection of the autonomic anxious arrangement. Non-essential function, comprise digestion, be reserved. Concentrated blood flow to human skin plus kidneys endorse the let go of rennin, trigger the angiotensin - aldosterone path leading to liquid retention as well as hypertension. The struggle and responsive results as of corticotrophin release feature from the hypothalamus, motivating to liberate of adrenocorticotropic hormone beginning the pituitary. These affect a free of cortical as of adrenal cortex.Cortical(external part of brain) gear are farreaching, counting lipolysis,(charbi) gluconeogenesis as well as reducing irritation. (Tortora and Grabowski, 2003). The body compensate for the special effects of stress as maximum possible. Three phase of pressure be describe as the universal accepted syndrome: dangerous or alarm phase, confrontation as well as fatigue

With so a lot of physiological response, there are many symptoms of anxiety that contrast with all individual, considerably, stress cause body muscle tension (HSE, 2007), exacerbate Norman's uneasiness, and influence his fineness of life. 


\section{Health Policy and Ladies Health Workers Stress During Fields Work: Case Study of District Muzaffargarh}

\section{The Health Careers}

The Penny Kane that is senior associate, as the part of Melbourne: office on behalf of sexual characteristics/ gender as well as Health level of care provided to women transversely the world encompass traditionally been owed the key responsibility meant for given that care to the infirm plus the elderly, particularly within, family. A few women, by the side of some period in their lives, flight the prospect of supplementary with nursing a sick or disable child, associate, parent or supplementary relative, whether individuals relatives like natal or acquire through wedding. A number of such episodes are short-term; numerous others, though, engage long-term difficult care for persons who are anguish profound as well as strict handicap. Divergent to what is occasionally believed; relatives/ family care for persons who need assist for the reason of disability that is the prime type of be concerned in industrialized as well as increasing country. An Australian research survey of helpful in family.(ABS, 1995)

Propose that a 3rd of those citizens who are working are kind for an adult, mostly an older human being The 'typical worker in such situation spirit be female, matrimonial and between the fourth and $50 \mathrm{y}$ of epoch/ age; surrounded by the health troubles faced by human resources who are as well careers, fatigue, responsibility plus worry as well as substantial conditions similar to back troubles were ordinary. The rest and sick leave For the health worker to give additional care exacerbate the troubles between a number of employees when case role may finish, the job opportunity option be concentrated lemmatized for those they have been away from labor force for a numeral of years. Four fifths belong to Australian careers who wish to re-enter the labor force thought that limited knowledge/ experience or along with age make it hard for them to discover a job another study, long-term possessions of care giving, reported those persons are the part of more than ten years be generally fewer likely to survive in a job the females careers who do have job, whichever for full-time or part-time, actually face the challenge of numerous role in a mainly acute structure, so most of women, mostly in Africa, the AIDS outbreak has bring additional concern. AIDS patients be predominantly care by female relatives, who might practice tension as of, and condensed make contact with, neighbors. Some of the women careers have had to reduce their profits earning actions that may cause the burden on families. Caregivers comprise, ever more, to support both kids and old citizens, as the pandemic deplete the position of youthful in addition to middle-aged adults

\section{Mentally Preparedness during Pandemic and Safety Measures}

i. At first step regulate your attitude as scientific perspective, for the duration of early stage of the pandemic outbreak, specific knowledge on the risks \& prevention of corona may cause a sense of anxiety as well as panic amongst the community, which be exacerbate by rumor. Comprise confidence in the convincing labors for anticipation, organize and faith scientific study answer the disease. Stay disappeared from fear. Recognize anxiety and panic, a small number of people can stay peaceful.

ii. The enlarged number of confirmed corona cases would lead towards the hypothesis that novel corona is present ubiquitously and is unavoidable, cause anxiety along with fear. That is ordinary to recognize the status; avoid unnecessary self-blame on behalf of feeling such emotions.

iii. Keep a regular and well lifestyle: sufficient sleep, a strong reasonable diet of varied food group, a habitual work routine which could help, distract ourselves from the corona epidemic, in addition to a sensible exercise treatment.

iv. Permit physically to let off steam as soon as you feel essential. Irregular respiration, expression of grief, shouting, exercise, singing, talking, chatting, writing and sketch can help discharge anger, anxiety also divert your concentration, and calm down successfully. Watching television or listen to music at residence also helps to relieve anxiety. 
v. Calm down and cope with your emotion. Entertainment technique can help you let go your negative emotion such as stress, depression, and worry.

There are numerous ways of leisure so the key to successful rest is to realize the basic values of the technique and carry out, entertainment during hallucination. Maintain a measured, steady \& deep breathing throughout the whole procedure, and feel hot energy graceful through your remains with prophecy. Muscle rest; Relax your parts of body especially, head, arm, trunk also legs successively. Maintain the surroundings quiet, diffuse the lights also minimize sensory stimulus. A straightforward 5step leisure cycle consists of: focus, concentration, relaxation throughout deep breathing; so this is an easiest and relax way that be able to be used in any condition wherever you feel worried. Steps: stand up and exercise your body, shoulder's to some extent close eyes, take deep breathe slowly. It regularly take just a small number of minutes to feel comfortable. (6) Seek specialized support. Seek psychotherapy or medical cure to unresolved stress, anxiety, horror, irritation, sleep disorder and physical reactions; On a diverse note, to quarantined, supposed patient manifest tremendous emotions in addition to behaviors, anticipation, control professional ought to believe the promising onset of psychiatric disorder, and drive the self in case to psychological health institution and workers. Such great emotions in addition to behaviors contain: anxiety, sadness, hallucination, agitation, uncontrollable and shocking verbal communication or actions, even violent, negative response or avoidance of quarantine or suicidal ideation. (zu, 2020).

\section{Objectives}

i. $\quad$ To explain in what ways lady health works feel stress especially during field's activities.

ii. To find out the causes that they create stress during operational activities and off duty hours

iii. In what ways 'COVID-19 increase fields stress especially during community services.

\section{Limitation}

This study is conducted during the pandemic, for the personal safety and purposed sop's were followed, There are $98 \mathrm{UC}$, with the use of quota sampling data was collected from just 1 UC staff, especially focuses on LHW's issues that they face during fields, data is collected through phone calls and selected the health workers from the UC Pattalmunda, Tehsail, M.Garh Punjab, Pakistan.

\section{Review of relevant literature}

Identified muscular health poor conditions; amongst health personnel. In addition, the expert recognized other physical condition risk for health workers because the danger of infectivity things psychological stresses; as well as long working hours, in a what ways can unpack the health workers themselves be asked to recognize their own perception of health harms associated by means of their occupation, their furthermost concern be the risk of illness, followed by the corporeal effort - and commonly uncomfortable posture - which their employment involved. Inadequate staffs, and short holidays,were further sources of anxiety. These conclusion are augmented by a study of pressure in health occupation (Heim, 1992)

Which originate that stress was supplementary pronounced between health workers added than physicians and more among women than men, partly because of the dual workload of family care and professional worker? The type of stress suffers by health employees allied to their slam involvement through patients, workload in addition to lack of self-government. The occupational health troubles of careers thus become visible to be comparable whether otherwise not the career is paid used for the employment.The major cause of work-related stress attached to workload pressures and interpersonal 


\section{Health Policy and Ladies Health Workers Stress During Fields Work: Case Study of District Muzaffargarh}

relations, together with bullying, aggravation in addition to difficulty by means of better; work change, as well as tasks and reduction of wealth (HSE, 2014). A (Govt. 2012) survey: unpack there are 48 percent of the British workers deliberation; they be worried mainly of time along with 47 percent work performance issue as a key reason.

\section{The workplace pressure / stress on individuals}

Stress decline when stressors are concentrated. Similarly, anxiety continue exclusive of a clear reason on the way to the individual. Nervousness and stress be closely connected with comparable signs along with symptom; concern may be related with depression since the most ordinary mood confusion seen in main care (Kumar and Clark, 2012).Citizens through low down psychosocial possessions are additional possible to succumb to disposition trouble when pressure levels augment despite experience not many stressors (DeLongis et al,1988).

The generation often undertakes the labor household tasks of missing staff. This might guide to spiraling absence amongst co-workers, who are stressed out as of the additional liability (HSE, 2014).This qualitative case study consisted the evaluation of an worker, Norman, in arrange to make sure his health to revisit to his role exclusive of impacting lying on his physical condition (Palmer et al, 2013).

He describe earlier short-term absence resultant from nausea in addition to vomiting, connecting these to his nervousness/ anxiety at presence work. In the earlier five headed for six weeks, in adding to nausea he as well referred to complexity resting, agitation, loss of appetite and palpitations plus reflection on his low down self-esteem. Mirror image be able to be unconstructive consequence of stress. Genet and Siemen (2012) claim the reflection moderate the relation amid unlikable daily belongings in addition to negative temper. Although unnecessary reflection is maladaptive, McFarland et al (2007) agree that a number of incomplete self-focus be able to be useful. Norman felt uneasy about chronic to the similar situation along with was access counseling hold up to help out anxiety managing. Hunsley et al (2014) in three countries, India Bangladesh and Pakistan the birth ratio is $27 \%$ as compare to globe. But a dangerous, unbalanced 34\% of motherly death (WHO 2004, Population Reference Bureau 2004). McCarthy and Maine (1992) focuses on the availability of health facilities and utilization (ANC).One indicator was missed gender as a leading factor of maternal health.

CIA (2020), so the world is facing pandemic and its taking the life of people without any age discrimination while after china, Iran, Italy America, European countries are more affected, Pakistan is following china model partially while have implemented lockdown in Sindh province, Pm say if we assure $100 \%$ lockdown than our country people will die due to poverty. So this is complex situation, what is favorable or not, but this is hard time in the history of world.

\section{Social Aspects of Policy and International World}

He said that Our common, enemy is novel corona virus, but he explain that another enemy is also a "info emic" that are community misinformation for "COVID-19 for the promotion we need to discourage the misconception and promote the facts that are stapled with corona along with scientific finding hope and solidarity more than despair and division (Guterres, 2020)Monetary along with Financial Stability for the period of the 'COVID-19 epidemic Global assistance to harmonize financial policy must be on top in financial agenda. There is a uncertainty and hard financial environment, dealings of financial insecurity such as equity marketplace volatility augmented stridently in countries in the region of the globe; supply market in major economy, like as the U.S, the Euro area, also Japan are harshly decline and witness a flow in obscure volatility as skittish investor tried to factor in the latest risks factors during new 
virus.(Adrian, 2020) The victory of the pace of revival will depend significantly on global economy policies undertaken during period of the 'COVID-19 crisis. (Giovanni Dell'Ariccia, 2020) The virus is thought to spread mainly from person-to-person. Between people who are in close contact with one another (within about 6 feet). Through respiratory droplets produced when an infected person coughs or sneezes. These droplets can land in the mouths or noses of people who are nearby or possibly be inhaled into the lungs. (university, 2020) Was fresh itself for a high risk of across the border infection. Contained by more than 2 months from Jan 23 when the 1 st case of novel corona was detected in neighbored country Vietnam, there were confirmed 239 cases without deaths (La, 2020) There are 416686 confirm cases all over the world till 12:00 pm as per Pak Standard time 26-March 2020 also website show 18,589 confirmed deaths, its reached into 197 countries of the world. (WHO, 2020)

\section{Research Methodology}

Researcher have conducted One-on-One meetings and collected data from 4 flw's, to understand the problems related to operational, fields activities and issues faced by the flw also how the 'COVID-19 pandemic have created issues to snub the struggle that were make by the flw's to change the behavior of community .also learn about the present level of self-confidence, spirit and stress also included the personal observation have measured the status and routine Along with developmental goals connected to social life of workers and in what ways communication for development can be ensured .

\section{Guide for One on One Meeting}

During meeting, with the help of interview guide especially learn about the respondent obstacles, that are against the goal achievement that are very much necessary to removed them urgently, During the meeting have discussed the specific issues closely related to flw's stress, work, reporting, other staff behave, managerial issues, community behave, epi , opv refusal behave, equality and equity, what kinds of the issues flw's are facing and in near future what type of the issues can be faced and have provided the value-added feedback, mental health psycho social support during interview on humanitarian grounds, that don't have any effects on results of study: for the improvement and take information till data saturation.

\section{Importance of One-on-On Meeting}

One on one meeting easily can built confidence and talk clearly about the objective and easily can write , learn a lot from the flow's connected with the objectives of research. During one on one meeting family permission was taken from the concern members.

\section{How often phone calls / One-on-One meetings can be held for data collection}

Mostly on to one meeting can be arranged with the gape of every two but due to pandemic will collect data through phone calls. if the respondents feel any issue or emergency, meeting will be canceled and postponed on second day as per convents the case were studied by the researcher were 10 and sample were selected on the behalf of purposive sampling.

\section{The length in respect of time for One-on-One meetings}

The meeting will be comprise on 30-40 minutes and the ideal meeting time/ phone call is just 30 minutes, especially will be divided on 10 minutes for researcher, 10 minutes for respondents , 10 minutes for sharing information related to research topic. 


\section{Pro-activation for One-on-One meetings/ Phone Calls}

Researcher have shared the research interview guide through whats-app / email /sms/ phone call. I have managed two copies one for respondents and other for record.

\section{What should be unpacking and covered?}

Association the call/ meeting will start as per interview guide a question like in what way you feel mental stress? Also at the end of this discussion, will analysis the trend of phone call and important passage.

\section{Value-Added Feedback}

I have added, positive advice as needed on the way to support for prospect. Have used this time to facilitate employees, be there aware and leveraged to the advantage of the team as well as group for change to their behavior as per situation for personal safety, they must should has have personal urge to understand, what and why need to be change; so that will be able to take necessary steps for successful.

\section{Data collection}

The data was collected during the one on one meeting, particularly interview guide were used

\begin{tabular}{lc}
\multicolumn{2}{c}{ Case study No. 1} \\
Name & S.A \\
Education & 10th \\
Department & Health. \\
Work experiences & 27 year. \\
District & M.Garh \\
Gender & Female
\end{tabular}

\section{Bibliography of Respondent}

Saleema aziz LHW is working from last 27year. Have good experience, she was joined hospital when a employee left job during 1997. She has passed $10^{\text {th }}$ and currently doing work as a LHW.

\section{Main Story, During Fields}

She explain that there are cretin reasons of stress, like child management, at home along with deity, not proper time given to family for children's socializations but we try to follow the time line, over load is also a cause of stress, she said that at a time just can performed single task/ work: but when supervisor give extra task than that time feel huge stress. Fields work is not simple, there are many more dangerous situations, like dog barking, accidents,community misbehave, media reporting, explanation's and in a some ways stress linked to hospital staff behave that the staffdo at hospital when community go for treatment, where there are shortage of vaccinae, medicen, staff on leave etc community show anger at fields staff this is unjust and awful response of community, also face issue when epi vaccination/ community session . door to door mobilization, Mother child health issues addressed to local members they try to they take revenge from LHW's. Community takes extra support from LHW's like make call to LHW's, on Sunday and other holidays after deity hours. She shares extra things like community cannot 
give protection from animals' dog, such situations extent the psychological stress of health workers regards duties.

\section{Some Cause Behind Stress}

She is facing issue that are like personal disputes,like property, old quarrels of runaway women's, murders ,but she said that mostly they ignore such things due to job and as a employee of government, sometime taken, threat from community like when children's feel fever after vaccination,( injections Eupenta) other thing that mainly disrupt the rest of family and bounded are community make late night calls for delivery/ children's birth. No leave issue, mostly take rest form lhs. Less hr, and extra hard to reach Ares's pockets.

\section{'COVID-19 Fields Stress}

Community not show anger, stress, mostly people don't hate, also provide protection considered like family members, have trust, the other aspect mostly community don't follow the 'COVID-19 related the sop's, hand washing not being done till 20-30 seconds ,not ensuring social distance of 6fit minimum. Sometime educated community members also call this westerns agenda,but uneducated are more worse regards 'COVID-19. Also she explains that government has not given personal protective equipment, but we are at risk, she said that there is less dander we trust on Allah almighty. Community don't follow the health instructions, people mainly become the cause of info emic.People say that don't move towards hospital they will inject a poison injections. "She say that personal communication is very important to acquire the epi, 'COVID-19 targets, and bcc.

\section{Case study No. 2}

$\begin{array}{cc}\text { Name } & \text { F.M } \\ \text { Education } & \text { middle } \\ \text { Department } & \text { Health. } \\ \text { Work experiences } & 12 \text { year. } \\ \text { District } & \text { Muzaffargarh. } \\ \text { Gender } & \text { Female }\end{array}$

\section{Bibliography of Respondent}

Fatima LHW is working from last 12 . Have high-quality work experience, she be joined hospital while an employee not here to join for job during 2008. She has passed ${ }^{\text {th }}$ class and at present doing employment as a lady health worker.

\section{Main Story, During Fields}

She give details that there are many more reason of mental stress, approximating child supervision from women's pregrency to 15 year age, at home along with duty, not accurate moment given to family for children's socializations excluding we try to pursue the time line up, over consignment is as well a cause of stress, she supposed that on a time immediately can perform on its personal task: but when administrator give additional task than that moment in time feel massive stress so the field employment is not straightforward, there are several more dangerous situation, similar to :dog barking, during field activities accidents ,the public misbehave, social media coverage, explanation's furthermore in a some conduct stress associated to rest home staff perform that the organization do at rest home when community go for dealing, where there are deficiency of vaccine, medicine, staff , happening leave et cetera the people show irritation at fields staff this is unjust furthermore awful retort of society, also face issue while epi immunization/ community conference . Door to door mobilization, Mother child health 


\section{Health Policy and Ladies Health Workers Stress During Fields Work: Case Study of District Muzaffargarh}

issues address to local member they try to they take revenge early LHW's. Group of people takes additional support starting LHW's like compose call to LHW's, on Sunday ,furthermore other holidays after duty hours. She shares additional things like the people cannot give fortification as of animals' dog, such situation point the psychological stress of wellbeing of employees regard duty.

\section{Some cause behind stress}

She is facing issue that is for example:

i. Local dispute, associated to property, old quarrel of Honor killing etc.

ii. Customary practices, murders, but she said that mostly they ignore such things due to job and as a employee of government.

iii. Some time taken, threat from community like when children's feel fever after vaccination, (injections Eupenta).

iv. The things that principally interrupt personal life; community make late night calls for delivery/ children's birth.

v. Leave issue, less hr, and extra hard to reach areas, community miss information, and society traditional stories linked with 'COVID-19, mostly face issue when they face trouble due to 'COVID-19.

\section{'COVID-19 Fields Stress}

Community show anger, pressure, mostly citizens don't hate, as well provide safety measured similar to relations or family members, have trust, the other aspect mostly community don't follow:

i. The 'COVID-19 related sop's of hand washing, till 20-30 seconds, not ensure social distance of 6 fit lowest.

ii. Sometime educated community members also call this American agenda.

iii. But uneducated are more worse regards 'COVID-19.

iv. Also she explains that government has not given personal protective equipment.

v. But we are at risk, she said that there is less dander we trust on Allah almighty.

vi. Community don't follow the health instructions, people mainly become the cause of

vii. Info emic, community says that don't shake hand to hospital and field staff they may cause to spread 'COVID-19 or they may be affected, suspected dare to excessive work and community engagement.

viii. They have poison injection, May they inject particularly she explain that due to such reamers mostly community parents become refusal for epi vaccination

ix. $\quad$. "She says that personal communication is very important to acquire the epi, 'COVID-19 targets, and to engage the community power structure for refusal coverage.

\section{Case study No. 3}

$\begin{array}{lc}\text { Name } & \text { K- A-S } \\ \text { Education } & \text { 10th } \\ \text { Department } & \text { Health. } \\ \text { Work experiences } & \text { 15 year. } \\ \text { District } & \text { M.Garh } \\ \text { Gender } & \text { Female }\end{array}$




\section{Bibliography of Respondent}

Kishwer Abdul Sattar LHW is working from last 15. Have good experience, she was joined hospital when a employee left job during 2005. She has passed $10^{\text {th }}$ and currently doing work as a LHW.

\section{Main Story, During Fields}

She give details that there be cretin reason of stress, similar to child management. Family extra stress due to work load: she said that at a time immediately can performed single job/ work: but at what time supervisor provide extra mission than that moment feel enormous stress. Fields employment is not straightforward, there be many more hazardous situation, like dog bark, accident, society misbehave, media coverage, explanation's as well as in a some habits stress connected to hospital staff act that the staff do at hospital whilst community go for dealing, whereas face deficiency of vaccine, medical. door to door mobilization and community issues from the 'COVID-19, Mother child health issues address to local member they seek to they take payback from LHW's. neighborhood takes extra support as of LHW's like make call to LHW's, lying on holiday along with after duity hours. Also argue that community cannot provide protection as of animals' dog, such situation; amount the psychological stress of healthiness employees regard duty.

\section{Some Cause Behind Stress}

She feel extra stress, vomiting and community extra calls, sunday work and community misbehave along with personal attacks she said that mostly they ignore such things due to job and as a employee of government, a number of time taken, threat commencing community like when children's feel fever after vaccination, ( injections Eupenta) other thing that mainly disrupt the rest of family.

\section{'COVID-19 fields stress.}

i. Community dislikes the pictures and do not allow to take picks while government and private organization's force the evidence. (Community women's argue that the staff may misuse picks, they may send on internet or utilize for negative purpose .

ii. Community spread misinformation instead to fight against the 'COVID-19.

iii. Don't take care personally.

iv. Government do not like epi vaccination they feel it's not good for children's.

v. Community and Government less interested to solve the community issues.

vi. Community may don't allow ensuring community meeting.

vii. Aspect mostly community don't follow the 'COVID-19 related the sop's, particularly hand washing not being done till 20-30 seconds.

viii. Community not ensuring social distance of 6 fit minimum.

ix. Some time educated community members also call: it's all false.

x. Community openly say them its government: policy to reduce the population and health staff is taking life of many more community members through being injected poison injection, while government take lot of money from International organization as per the human body rate is more than 4 lack. Such situation is very serious and creates problems for community health workers.

xi. She feels stress during fields activities, mostly face issue related to ill health, vomiting and head ach, she don't use hand sanitizer but feel lot of stress.

xii. Family tasks along with duty, Sunday work, late night work.

xiii. Communities misbehave particularly after the vaccination when child feel high fever, community argue that you should live at home don't spared it.

xiv. Community call name, silent refusal for polio campaign/ community improper demands from staff. 


\section{Health Policy and Ladies Health Workers Stress During Fields Work: Case Study of District Muzaffargarh}

\section{Case study No. 4}

$\begin{array}{ll}\text { Name } & \text { H-B. } \\ \text { Education } & \text { Middle } \\ \text { Department } & \text { Health. } \\ \text { Work experiences } & \text { 16 year. } \\ \text { District } & \text { M.Garh } \\ \text { Gender } & \text { Female }\end{array}$

\section{Bibliography of Respondent}

Haleema LHW is working from last 16 Have good experience, she was joined hospital when a employee left job during 2004. She has passed ${ }^{8 \text { th }}$ and currently doing work as a LHW.

\section{Main story, during fields}

Community counseling along with pw, awareness is basic task that LHW's did every day, she explain that there are many more issues that we are facing like motorcycle driving issues mostly male counterpart doing work without any financial support, other issues related to work are community mistrust due to 'COVID-19, community. She feel time management, multiple activities at a same time along with over load, on holiday and Sunday, late night call to take support especially for 1034 helpline , for delivery. When we move at fields especially into hard to reach pockets people don't pay attention for vaccination nor do they support to save us from dogs and other harmful animals.

She give details that there be cretin reason of stress, similar to child management. Family extra stress due to work load: she said that at a time immediately can performed single job/ work: but at what time supervisor provide extra mission than that moment feel enormous stress. Fields employment is not straightforward, there be many more hazardous situation, like dog bark, accident, society misbehave, media coverage, explanation's as well as in a some habits stress connected to hospital staff act that the staff do at hospital whilst community go for dealing, where in attendance are deficiency of vaccine, medical. door to door mobilization and community issues from the COVID-19, Mother child health issues address to local member they seek to they take payback from LHW's. Neighborhood takes extra support as of LHW's like make call to LHW's, lying on holiday along with after deity hours. Also argue that community cannot provide protection as of animals' dog, such situation; amount the psychological stress of healthiness employees regard duty.

\section{Some cause behind stress}

She feel ill health due to extra stress along with the vomiting, misbehave, personal attacks (injections Eupenta) other thing that mainly disrupt the rest of family. Long distance during work, low human resources and extra work load on existing staff.

\section{COVID-19 fields stress}

i. Community dislikes the pictures while government and private organization's force the evidence, community lack of trust and misinformation refusal from vaccination after the video's on social media.

ii. Community stretch misinformation as a substitute to fight against the 'COVID-19. 
iii. Aspect mostly community don't follow the 'COVID-19 related the sop's, particularly hand washing not being done till 20-30 seconds.

iv. Community not ensuring social distance of 6 fit minimum.

v. Family tasks along with duty, Sunday work, late night work.

vi. Community call name, silent refusal for polio campaign/ community improper demands from staff.

\section{References}

Alexander MF, Fawcett JN, and Runciman PJ (2006). Nursing Practice: Hospital and Home. 3rd edition. Edinburgh, Elsevier.

Blows W (2011). The biological basis of mental health nursing. 2nd edition. Abingdon, Oxon. Routledge.

Tortora G and Grabowski S (2003). Principles of anatomy and physiology, 10th edition, Hoboken NJ, John Wiley \& Sons.

Health and Safety Executive (2007). Managing the causes of work-related stress. A step-by-step approach using the management standards. 2nd edition HSE books. Available online. Accessed 12 April 2016.

Zu, w. (2020). Corona Prevention . In Q. C. Shan Zhu. (Wuhan Center for Disease Control \& Prevention), Whun : Wang Zhou (Wuhan Center for Disease Control \& Prevention).

Heim, E. 1992, 'Stressoren der Heilberufe' Zeitschrift fur psychosomatische Medizin und Psychoanalyse 38(3):207-226

DeLongis A, Folkman S, and Lazarus Richard S (1988). "The impact of daily stress on health and mood: psychological and social resources as mediators". Journal of Personality and Social Psychology, vol.54(3), pp.486-495. Available online. Accessed 19 April 2014.

Gov (2012). Stress Survey. Available online. Accessed 19 April 2016.

Doyal, L. (1998) Gender and Health. Technical Paper WHO/FRH/WHD/98.16, Geneva: World Health Organisation.

Kumar P and Clark M (2012). Clinical Medicine, 8th edition, Edinburgh, Saunders Elsevier.

Palmer K, Brown I, and Hobson J (2013). Fitness for Work, 5th edition, Oxford University Press. Genet JJ and Siemer M (2012). "Rumination moderates the effects of daily events on negative mood: results from a diary study". Emotion, vol.12(6), pp.1,329-1,339.

McFarland C, Buehler R, von Rüti R, Nguyen L, and Alvaro C (2007). "The impact of negative moods on self-enhancing cognitions: the role of reflective versus ruminative mood orientations". Journal of Personality And Social Psychology, vol.93(5), pp.728-750.

Hunsley J, Elliott K, and Therrien Z (2014). "The efficacy and effectiveness of psychological treatments for mood, anxiety and related disorders". Canadian Psychology/Psychologie Canadienne, vol.55(3), pp.161-176. 
McCarthy, J. and Maine, D. (1992) A framework for analyzing the determinants of maternal mortality, Studies in Family Planning, 23, 1, 23-33.

Mumtaz, Z. (2002) Gender and Reproduction Health: a need for reconceptualisation. Unpublished PhD thesis presented to the University of London.

Bhutta, Z. (2000) Why has so little changed in maternal and child health in South Asia? British Medical Journal, 321, 809-12.

De Brouwere, V., Tonglet, R. and Van Lerberghe, W. (1998) Strategies for reducing maternal mortality in developing countries: what can we learn from the history of the industrialised West? Tropical Medicine and International Health, 3, 10, 771-82. 